\title{
Architect or Bee? Mike Cooley: the human spirit
}

\author{
Karamjit S. Gill ${ }^{1}$
}

Published online: 26 August 2016

(C) Springer-Verlag London 2016

As AI\&Society moves through its 30th anniversary and marches into the extraordinary times and uncertain world we live in, we celebrate the pioneering work and contributions of Mike Cooley in the shaping and evolution of the journal over the past 30 years. The journal is now a major international forum for socially responsive technology, far beyond the initial aspirations of its founding board members. Mike Cooley as the Founding Chairman of the AI\&Society Board has been a towering figure in the human-centred intellectual tradition, arguing for a unified cultural vision that embodies human centredness and the rich tradition of Italian Renaissance art and architecture. Mike has now reached a stage in his life with frail health and would like to pass on the baton to the Journal board members and future generations. In recognition of his work and inspiration, the AI\&Society Board would like to honour Mike in asking him to become Patron of the Journal as he steps down from being the Board Chairman.

Decades before concerns about the black swans of the algorithmic culture were raised following the recent financial crash; Mike Cooley expressed deep concerns about the human price of automation at the work place. He argued for an alternative human-centred vision of socially useful technology that facilitated the ethos of human-machine symbiosis that he saw as a collaboration of human judgement and the calculation capacity of the machine. It is interesting to note that values of the human-centred tradition of the 1970s are reformulated in the emergence of socially useful artificial super intelligence, Big Data and Internet of Things. Similar

Karamjit S. Gill

editoraisoc@yahoo.co.uk

1 Professor Emeritus, University of Brighton, Brighton, UK questioning of technology led to the making of the European human-centred debate of 1970s. During this era of the rationalisation of industry and the 'white of heat of technology', Mike Cooley together with a number of socially conscious thinkers felt perturbed about the hold of the scientific method of Taylorism and its implications for working life in the industrialised world, and by implication for the wider society. The concerns included the fear of automation of production processes, the mechanisation and by implication dehumanisation of the work place, the loss of human skill and expertise, and ultimately the replacement of the human worker by the robot, leading to mass unemployment and exclusion. On the same time horizon, the computer as a symbolic embodiment of instrumental reason was seen to go further than the machine, being made in the image of man; an imitation of a certain aspect of man in the sense that it ventured into the realm of the imitation of human thought. This was seen as a step towards the reproduction of some key aspects of human traits if not their replacement. There was further unease at the idea of venerating the machine to the point that there is no difference between humans and machines, and between human thought and machine thought. This made human-centred thinkers recognise that humanity should take this risk seriously. The human-centred intellectual tradition saw problems with this instrumental rationality early on; it was clear that human activity itself could not be adequately understood, prescribed or pre-designed using the instrumental approach of Taylorism. Central to the humancentred vision is the notion of a symbiosis of the tacit dimension and the objective. This conceptualisation is founded on the belief that through the interplay between the richness of human skill and the calculation capacity of the machine, we can create a work place model that leads to much enhanced productivity and enriched human expertise 
through the combination of human ingenuity and technological innovations. Cooley, however, warns us of the danger of the objectification of human knowledge and experience into information and data; this turns human judgement into calculation and in the process, turns the human into a robot and an appendage of the machine.

Over the last 30 years since its inception, AI\&Society has gone through its own evolution responding to the ongoing interlocution between technology and society, with its focus on human-centred systems during the first decade followed by its focus on machine intelligence, and now on knowledge, culture and communication. The socially responsive ethos of the Journal is rooted in the human-centred movement of the Lucas Workers' Plan of 1976 (Cooley 1987), encapsulated in the statement that 'there cannot be islands of social responsibility in a sea of depravity'. Mike Cooley as the architect of the Lucas Plan highlighted the problem of the technological advanced society of 1970s in noting: 'the appalling gap between what technology could provide for society, and what it actually does provide'; 'the tragic waste our society makes its most precious asset - the skills, ingenuity, energy, creativity and enthusiasm of ordinary people'; and 'the myth that computerisation, automation and use of robotic devices will automatically free human being from soul destroying, backbreaking tasks and leave them free to engage in more creative work'. The Lucas Plan not only provided a critique of the mindless introduction of new machines and new work organisation, it laid the foundation and framework of the British Human-Centred movement. It conceptualised human-machine symbiosis as an alternative potential for work life, whilst at the same time becoming a catalyst for humanistic movements such as 'Democratic Participation' (Scandinavia) and 'Humanisation of Technology and Work' (Germany). These European human-centred movements provided a basis for the establishment of the 'Anthropocentric Systems and Technology' programme of the European Union during the 1990s.

It was during the summer of 1981, at a summer school at the University of Sussex, that I was introduced to Mike Cooley's seminal book, Architect or Bee? The Human/ Technology Relationship, edited by Shirley Cooley. A revised version of the book came out in 1987 under the same title but with a new subtitle that reflected the far-reaching impact of technology on society: Architect or Be? The Human Price of Technology (Cooley, ibid). This seminal work remains at the heart of the evolution of AI\&Society.

During the early 1980s, I launched and directed a multimedia project, CAAAT (Computer Aided Animated Arts Theatre) that formed the basis for the SEAKE (Social and Educational Applications of Knowledge Engineering) Centre at University of Brighton. The SEAKE Centre organised annual workshops and conferences on Artificial
Intelligence for Society, with the first conference held at the University of Brighton in 1983. This 1983 conference was chaired by the late eminent philosopher, Prof. Michael Dummett, and attracted a wide range of international participants including Maggie Boden, Alan Bundy, Massimo Negrotti and Achille Ardigo (Italy), Ajit Narayan, David Smith, Richard Ennals, Satinder Gill, the late Bob Muller, Janet Vaux, Mahesh Uppal, the late Swasti Mitter, all of whom were to join the founding Boards of AI\&Society. The work of the SEAKE Centre and the CAAAT projects became the catalyst for my sabbatical year at GLEB (Greater Enterprise Board, London) in 1985-86, to work with Mike Cooley, who was then the Executive Director of Greater Enterprise Board (GLEB). In 1981, the new Labour administration of London, under the leadership of Ken Livingstone, the first Labour Mayor of London, invited Mike Cooley to head the technology division of GLEB. Mike pioneered the setting up of Technology Networks in London in collaboration with universities, trade unions and community organisations. It was during this period at GLEB that Mike introduced me to the European researchers, Peter Brodner, Lauge Rasmussen, the late Howard Rosenbrock, Felix Rauner, Martin Corbett and John Palmer of the Guardian Newspaper, all of whom later joined as founding members of the Journal Boards.

During my time at GLEB, Mike sponsored my research visit to the USA, and introduced me to the late Prof. Joseph Weizenbaum, who in turn introduced me to Marvin Minsky, Seymore Pappert, Hubert Dreyfus, David Noble, Terry Winograd and Bob Lawler. In New York, I met with James Finkelstein and at New Mexico I met Derek Partridge, and Maggie Boden introduced me to Daniel Dennett. They were all to join the Journal as founding members of its Boards. It was during my visit to MIT that the idea of launching an international journal on Knowledge and Society was formulated, during my seminar at the MIT Media Lab organised by Bob Lawler. Both Profs. Weizenbaum and Marvin Minsky supported the idea of a Europe-based journal. On my return to GLEB, I proposed to Mike that we launch the Knowledge and Society journal and he agreed to support it with a focus on the humancentred ethos of science and technology. The proposal for the journal was put to a number of publishers, but it was Springer that responded positively to the idea of a European AI journal. I had earlier edited a book, Artificial Intelligence for Society (Gill 1986), that was based on the proceedings of the 1983 conference with the same title. This was published by Wiley, and coincidently Jamie Cameron who was with Wiley during the publication of my book had moved to Springer as Managing Director to set up their London office, and he liked the idea of inaugurating his move with a new international journal dealing with technology and society. It was Jamie Cameron who 
suggested the title AI\&Society whilst accepting Mike's subtitle of human-centred systems. So in July 1986, AI\&Society: Journal of human-centred systems was launched by Springer. The North American inauguration of AI\&Society took place during the annual conference of Computers for Social Responsibility in 1987, chaired by Terry Winograd and supported by Doug Schuler, and Doug later joined the advisory board of the Journal.

The focus of the tacit dimension of knowledge in both the Journal and the AI for Society book, attracted a visit to Brighton (where I lived) by two Swedish researchers, Bo Goranzon and Ingela Josefson, who were then leading a European research network on Language, Culture and Artificial Intelligence and were planning an international conference on the same theme. The founding members of AI\&Society, Mike Cooley, Hubert Dreyfus, Tore Nordenstam, Kjell Johnanessen, David Smith, Richard Ennals, Massimo Negrotti and myself participated in the conference of Language, Culture and Artificial Intelligence, held in Stockholm in 1988. Soon afterwards in 1989, a symposium on human-centred systems was organised by the SEAKE Centre to explore a collaborative future in humancentred systems between European and Japanese researchers. The symposium was chaired by Mike Cooley and hosted by the visiting Japanese research delegation sponsored by the Japanese Ministry of External affairs and led by the late Yuji Masuda and the late Fumihiko Satofuka, both of whom later joined the AI\&Society Boards. This initiative led to the EU-Japan collaboration in Anthropocentric Systems and Technology under the FAST programme of the European Commission. AI\&Society became a catalyst and forum for promoting the contributions of this collaboration, cultivating cultural perspectives of the human-centred movement beyond the European tradition. This collaboration laid the foundation for the EU-India Cross-Cultural Innovation Network coordinated by Karamjit S Gill. This collaboration between European and Indian universities was built upon the human-centred ethos of socially useful systems and technology. Whilst European researchers, Francesco Garibaldo from Bologna, David Smith from Wales and Lauge Rasmussen from Denmark, were already involved in AI\&Society, Mike Cooley introduced Dietrich Brandt from Aachen to join the EU-India Network and the Journal, and along with the India network members Ashok Jain and Partha Banerjee, they became members of the Journal boards. In recognition of his international contributions, Mike Cooley was invited by the European Commission to chair the steering committee of the EU-India Cross-Cultural Programme. AI\&Society again became a catalyst for bringing together research networks from Europe, Japan, India, Australia and the USA for promoting the human-centred ethos of science and technology. As the Journal progressed into twenty-first century, Mike welcomed Victoria Vesna, Sha Xin Wei, Toyoaki Nishida and Larry Stapleton to the editorial board. His human-centred vision of technology and society has always been warmly supported by our Computing Editors, Beverley Ford and Rachel Roberts at Springer, London.

Mike's contribution to the evolution of AI\&Society over the last 30 years is just an illustration of his international achievements, which include the launch of the LUCAS Plan in 1970s, the award of the Alternative Noble Prize in 1981, the setting up of Technology Networks at GLEB in 1980 s, the steering and chairing of international workshops, conferences and symposia on human-centred systems, and his continuing emphasis on 'purpose' over 'cause and effect' in designing systems and technology that enrich human creativity and liberate us from the militancy of automation. Cooley sees the computer as not an isolated phenomenon but rather as a technological continuum of human history over last 400 years or so. During this period, humanity has witnessed the decline of feudalism, the growth of capitalism, the weakening of religion as the leading edge of European society, and the emergence of Cartesian science. The central issue of concern to Cooley has been our overwhelming faith in science and technological change. Science, to him, is a shallow and arid soil in which to transplant the sensitive and precious roots of our humanity. Science and technology are now leading edges in society - in rather the same way religion was in mediaeval times. This new religion confuses people with analytics and technical jargon, and the apparent rationality of symbolic logic bludgeons people's common sense. It is no surprise that there is a concern among many socially oriented researchers about the existential risk of artificial super intelligence, and ethical and social implications of big data and Internet of Things. Cooley is concerned that we confer life on machines and diminish ourselves, and consequently we are gradually becoming observers of life rather than its active participants.

Anthony Barnet sums up Mike's vision of humanity in his Introduction to Architect or Bee?: for Cooley, 'the future is not "out there" in the sense that a coastline is out there before somebody goes to discover it'. It has yet to be built by human beings (Cooley, op.cit). AI\&Society editors will always cherish Mike's humanistic spirit and generosity and welcome him in his new role of 'Patron' of AI\&Society.

\section{References}

Cooley M (1987) Architect or Bee? the human price of technology. The Hogarth Press, London

Gill KS (ed) (1986) Artificial intelligence for society. Wiley, London 